\section{Estudo \\ CoDebate}

em Testão

Plamejamento
Revista Estudo \& Debate, Lajeado, v. 28, n. 1, 2021. ISSN 1983-036X

DOI: http://dx.doi.org/10.22410/issn.1983-036X.v28ila2021.2675

\title{
SEGURANÇA ALIMENTAR, AGRICULTURA FAMILIAR E ABASTECIMENTO DE ALIMENTOS EM TEMPOS DE PANDEMIA: ENSAIOS PARA O ESTADO DO AMAZONAS
}

\author{
Beatriz Jean Maia ${ }^{1}$, Elane Conceição de Oliveira ${ }^{2}$
}

\begin{abstract}
Resumo: Este trabalho tem como objetivo contribuir com as discussóes sobre segurança alimentar, agricultura familiar e abastecimento de alimentos em tempos de pandemia vigente com foco no estado do Amazonas (AM). Metodologicamente, essa pesquisa é quali-quantitativa de caráter exploratória, com levantamento bibliográfico e de dados estatísticos sobre as temáticas em questão. Os resultados revelaram haver uma relaçáo direta entre segurança alimentar e nutricional (SAN) e agricultura familiar (AF). A AF é um setor essencial e estratégico em tempos de pandemia, pois, além de garantir a segurança alimentar do país, a agricultura brasileira foi o único setor sem retraçáo econômica até o momento. No AM, $90 \%$ da agricultura é familiar baseada em sistemas agroflorestais diversificados e com forte concentração de estabelecimentos rurais inferiores a 10 hectares. Muito embora os produtores rurais produzam alimentos e abasteçam a regiáo, o AM ainda é grande importador de produtos alimentares (mandioca, farinha de mandioca, milho e feijão), o que dificulta a soberania e a segurança alimentar da população amazonense. No entanto, a agricultura de base familiar amazonense é um canal para reduzir o nível de pobreza dos povos ribeirinhos e para promover o desenvolvimento local sustentável na regiáo.
\end{abstract}

Palavras-chave: Segurança alimentar. Agricultura familiar. Pandemia. Amazonas.

\section{FOOD SECURITY, FAMILY FARMING AND FOOD SUPPLY IN PANDEMIC TIMES: TRIALS FOR THE STATE OF AMAZONAS}

\begin{abstract}
This paper aims to contribute to the discussions on food security, family farming and food supply in times of current pandemic focusing on the state of Amazonas (AM). Methodologically, this research is qualitative and quantitative with an exploratory character, with a bibliographic survey and statistical data on the themes in question. The results revealed that there is a direct relationship between food and nutrition security (SAN) and family farming (AF). AF is an essential and strategic sector in times of a pandemic, since, in addition to guaranteeing the country food security, Brazilian agriculture was the only sector without economic retraction so far. In AM, $90 \%$ of agriculture is family-based, based on diversified agroforestry systems and with a strong
\end{abstract}

1 Graduada em Ciências Econômicas pela Universidade do Estado do Amazonas (UEA), mestranda em Ciências Sociais - desenvolvimento, agricultura e sociedade pela Universidade Federal Rural do Rio de Janeiro (UFRRJ), bolsista Capes.

2 Economista. Doutorado em Desenvolvimento Sustentável pelo Centro de Desenvolvimento Sustentável, Universidade de Brasília (CDS/UnB). Professora adjunta na Escola Superior de Ciências Sociais, Universidade do Estado do Amazonas (ESO/UEA). 
concentration of rural establishments below 10 hectares. Even though rural producers produce food and supply the region, AM is still a major importer of food products (manioc, manioc flour, corn and beans), which hinders the sovereignty and food security of the Amazonian population. However, Amazonian family-based agriculture is a channel to reduce the poverty level of the riverside peoples and to promote sustainable local development in the region.

Keywords: Food security. Family farming. Pandemic. Amazonas.

\section{Introduçáo}

A Cúpula Mundial de Alimentação, da Organização das Naçóes Unidas para Alimentação e Agricultura (FAO) relata que o problema da fome e da insegurança alimentar está relacionado à pobreza, sendo imprescindível erradicá-la para melhorar o acesso aos alimentos.

No Brasil, com 7,4\% da população vivendo na extrema pobreza (mais de 15 milhóes de pessoas) e $26,5 \%$ vivendo na condiçấo de pobreza (ou quase 55 milhóes de pessoas), conforme IBGE (2018), as preocupaçóes com a insegurança alimentar podem ser agravadas devido a crise de saúde pública sem precedentes causada pelo novo coronavírus.

Para Maluf (2020), era previsível que a comida - tanto sua disponibilidade como o acesso a ela - viesse a ocupar o centro das preocupaçóes e urgências no contexto de pandemia pelo qual estamos passando, ao lado e como complemento indispensável dos cuidados com a saúde das pessoas infectadas ou não pelo vírus mais recente. A preocupaçáo com ter o que comer para não passar fome, e que haja meios adequados para obter os alimentos sem risco de se contaminar, passou a estar na preocupação diária mesmo daqueles para quem comprar e comer não era mais do que rotina obrigatória, afirma o autor.

Mas, em todas as regióes do Brasil, já há um universo significativo e variado de produção, processamento e comercializaçấo de alimentos oriundos da agricultura de base familiar que circulam através de circuitos curtos, feiras, oferecimento de cestas entregues em domicílio (MALUF, 2020). Isto porque um ponto forte da estrutura agrícola brasileira é a grande quantidade de produtores localizados nos cinturóes verdes das cidades que abastecem os centros urbanos (SAES, 2020).

É importante destacar, nesse cenário de pandemia, que a agricultura foi a única atividade que ainda não apresentou retração econômica. No primeiro trimestre de 2020, o Produto Interno Bruto (PIB), afetado pela pandemia e distanciamento social, apresentou contraçáo de $1,5 \%$ e $0,3 \%$, sendo que a indústria $(-1,4 \%$ e $-0,1 \%)$ e os serviços $(-1,6 \%$ e $-0,5 \%)$ apresentaram recuo, enquanto a agropecuária $(0,6 \%$ e $1,9 \%)$ cresceu (IBGE, 2020) ${ }^{3}$.

Nesse cenário positivo do campo, a agricultura familiar é um setor essencial e estratégico em tempos de pandemia. Quanto a sua essencialidade, de acordo com o IBGE (2010), a agricultura familiar é responsável por garantir boa parte da segurança alimentar do País, como importante fornecedora de alimentos para o mercado interno, além do que ela representa $84,4 \%$ dos estabelecimentos rurais brasileiros. Quanto a sua estratégia, a

3 Taxa trimestre contra trimestre imediatamente anterior (com ajuste sazonal) e taxa trimestral em relação ao mesmo trimestre do ano anterior, respectivamente. 
importância da agricultura familiar se dá em função de sua concepção como desenvolvimento duradouro, geração de emprego e renda, segurança alimentar e desenvolvimento local (BEZERRA e SCHLINDWEIN, 2017; NIEDERLE, 2014; MATTEI, 2014; CORONA e PEREIRA, 2013; SCHNEIDER, 2003; ABRAMOVAY, 1999; VEIGA, 1996).

Os desafios continuam para o mundo e para o País. Além das preocupaçóes com a segurança alimentar e nutricional e o abastecimento de alimentos, a crise provocada pela doença covid-19 causou e continua causando desempregos, falência das empresas, turbulências financeiras, endividamento dos estados nacionais, entre outros problemas conjugados. É importante salientar que o isolamento adotado, embora acertado, não impacta homogeneamente a população, aprofundando as desigualdades sociais (PIRES, CARVALHO e XAVIER, 2020), de modo que ampliar a transferência direta de renda aos mais necessitados é fundamental (MALUF, 2020).

O objetivo do artigo é contribuir com as discussões sobre segurança alimentar, agricultura familiar e abastecimento de alimentos em tempos de pandemia com foco no estado do Amazonas. Buscou-se compreender de que maneira a segurança alimentar está inserida no desenvolvimento econômico do AM, bem como compreender as principais potencialidades da agricultura familiar como forma de promoção de um desenvolvimento sustentável local.

Além desta introdução, a seção dois relata as diretrizes metodológicas realizadas na pesquisa. A seção três aborda as inter-relações existentes entre segurança alimentar e agricultura familiar a partir de levantamento bibliográfico dos principais estudiosos responsáveis pelas discussões teóricas dessa temática no país. A seção quatro faz um panorama sobre o papel e a importância da agricultura de base familiar do AM, evidenciando características peculiares do meio rural da regiáo como prerrogativas eficazes para assegurar a segurança alimentar, o abastecimento de alimentos e o desenvolvimento local sustentável. Por fim, na quinta seção são apresentadas as consideraçóes finais.

\section{Metodologia}

Adotou-se para realização deste estudo, de caráter exploratório, a abordagem metodológica quali-quantitativa, tendo em vista que por "quali" foi feito o uso do caráter subjetivo e análise do contexto social e por "quanti" tratou-se do uso de números, métricas e a tradução dos dados obtidos na pesquisa para formas numéricas percentuais, elaboração de tabelas, quadros e gráficos.

Como procedimento técnico, optou-se pela pesquisa bibliográfica, tendo em vista a ampla cobertura dos fenômenos analisados a partir de materiais já elaborados. Priorizouse a revisão sistemática de artigos encontrados em periódicos qualis/capes para embasar a discussão teórica.

Utilizou-se dados estatísticos, em sua maioria com ano de referência 2017, para elaboração das discussôes relativas à agricultura familiar amazonense como segurança alimentar e nutricional e abastecimento de alimentos na região, conforme quadro abaixo: 


\begin{tabular}{|l|l|l|}
\hline Descriçáo & Ano de referência & Fonte da informaçáo \\
\hline Valor adicionado bruto & 2017 & Contas Regionais do AM/IBGE \\
\hline Número e área dos estabelecimentos agropecuários & 2017 & Censo Agropecuário 2017/IBGE \\
\hline Importaçóes interestaduais & 2017 & SEFAZ/AM \\
\hline $\begin{array}{l}\text { Valor da produçáo agropecuária (produtos } \\
\text { selecionados) }\end{array}$ & 2017 & SIDRA/PAM/IBGE \\
\hline Produçâao (em toneladas) de mandioca & 2017 & IDAM/SEPROR/AM \\
\hline Produçáa (em toneladas) de abacaxi e açaí. & $2014-2019$ & IDAM/SEPROR/AM \\
\hline PIB trimestral & 2020 & SEDECTI/AM \\
\hline Produçấo (em toneladas) de pescado (pesca artesanal) & 2017 & IDAM/SEPROR/AM \\
\hline
\end{tabular}

\section{Segurança alimentar e nutricional e a agricultura familiar: inter-relaçóes}

A temática da segurança alimentar e nutricional é um tema recente no debate nacional e tem relação direta com a agricultura familiar (CORONA e PEREIRA, 2013). Desde a década de 1990, o governo brasileiro tem buscado (por meio de programas e políticas de desenvolvimento) mecanismos não somente para saciar a fome, a inanição e a desnutrição alimentar, mas iniciativas que visam à segurança alimentar, com garantias da qualidade dos produtos, da distribuição, de mecanismos de acesso aos alimentos e, principalmente, do desenvolvimento local focado na agricultura familiar, complementa os autores.

Para tanto, de acordo com a Lei no 11.346/2006, que criou o Sistema Nacional de Segurança Alimentar e Nutricional (SISAN) ${ }^{4}$, a segurança alimentar e nutricional (SAN) consiste na realização do direito de todos ao acesso regular e permanente a alimentos de qualidade, em quantidade suficiente, sem comprometer o acesso a outras necessidades essenciais, tendo como base práticas alimentares promotoras de saúde que respeitem a diversidade cultural e que sejam ambiental, cultural, econômica e socialmente sustentáveis. O SISAN conferiu à SAN ampla abrangência, que, entre outras coisas, disciplina a ampliação das condiçóes de acesso aos alimentos por meio da produção, em especial da agricultura tradicional e familiar.

Para Corona e Pereira (2013), a política de SAN estende a dimensão da segurança alimentar para o desenvolvimento local, ao proporcionar que a agricultura familiar seja um dos campos de incidência dessa política, juntamente com outras formas de organização da sociedade, responsáveis pelos processos de produção, distribuição, acesso e consumo de alimentos. Desse modo, o governo procura executar a política pública de SAN preconizando o desenvolvimento de comunidades rurais e reconhecendo esse espaço como responsável pela produção alimentar, afirma os autores.

Para Vasconcellos e Moura (2018), o SISAN reúne múltiplos eixos temáticos que, se por um lado se organizam em setores distintos de governo, como são as áreas de agricultura e acesso à terra, ambiente, assistência social, cultura, direitos humanos e saúde, incluem temas transversais que permeiam importantes demandas da sociedade. Para Vasconcellos e

4 Integram o SISAM a Conferência Nacional de Segurança Alimentar e Nutricional (CNSAN), o Conselho Nacional de Segurança Alimentar e Nutricional (CONSEA), a Câmara Interministerial de Segurança Alimentar e Nutricional (CAISAN), os órgãos e entidades de SAN da Uniáo, dos Estados e e dos municípios. 
Moura (2018 apud Faustino, 2016), tal organização coloca os agentes públicos diante do desafio de "traduzir" o sentido da segurança alimentar e nutricional para os demais níveis de governo. Sua abrangência traz para o centro do sistema os conflitos inerentes a cada setor, exigindo da sociedade civil e do Estado capacidade técnica e política para impulsionar a política, superando entraves internos e externos ao SISAN, afirmam os autores. Mas, apesar da amplitude do conceito de SAN, de acordo com Belik (2003), três são os aspectos principais a serem trabalhados pela SAN: a quantidade, a qualidade e a regularidade no acesso aos alimentos.

Rocha (2012 apud Abramovay, 2006) explica que a valorização da agricultura familiar foi pautada a partir de três planos distintos: a) o plano intelectual por conta dos diversos estudos e pesquisas que permitiram estratificar e capturar toda a heterogeneidade da agricultura familiar no país; b) o plano de políticas públicas, principalmente após o Programa Nacional de Fortalecimento da Agricultura Familiar (PRONAF) e intensificação dos projetos de assentamentos de reforma agrária durante a década de 1990; c) o plano social, por último, a agricultura familiar corresponde a um conjunto de forças organizadas em movimentos sociais e sindicatos cuja principal bandeira de luta é a afirmação da viabilidade econômica da produção familiar.

E não menos importante, essa valorização tem se intensificado com a criaçáo da Lei $\mathrm{n}^{\mathrm{o}}$ 11.326/2006 ou "Lei da Agricultura Familiar", que institucionalizou as diretrizes sobre a formulação do PRONAF, estabelecendo o conceito de agricultor familiar e empreendedor familiar rural; com a criação da Lei no 12.188/2010, que instituiu a Política Nacional de Assistência Técnica e Extensão Rural para a Agricultura Familiar e Reforma Agrária (PNATER); com a criaçấo da Lei $n^{\circ} 13.839 / 2019$ sobre a ampliação das condiçôes de acesso aos alimentos por meio da produção, em especial da agricultura tradicional e familiar.

No que se refere à Lei da Agricultura Familiar, de acordo com Mitidiero Junior et al (2017), são três os grandes problemas dessa normatização:

a) a diretriz encontrada no inciso I do Art. $3^{\circ}$ pode ter permitido ocultamento de estabelecimentos familiares/camponeses, uma vez que limita até 4 módulos fiscais o que se pode considerar "agricultor familiar". O município de características agrícolas de Cruz do Espírito Santo, na Paraíba, possui como módulo fiscal a área de 10 hectares, isso quer dizer que o limite para ser considerado agricultor familiar é de 40 hectares (4 módulos fiscais), sendo que uma família de pequenos agricultores que detêm 41 hectares de terra, mesmo trabalhando sua terra unicamente com a sua família e comercializando o excedente produzido, não seria computada como agricultor familiar pelo recenseador. O município de Veranópolis, no Rio Grande do Sul, possui como módulo fiscal a área de 12 hectares, sendo 48 hectares o limite para considerar os estabelecimentos como de agricultores familiares. Com isso, qualquer família que trabalhe na terra usando unicamente ou predominantemente trabalho familiar, mas que possua uma área superior a 48 ha, náo pode ser considerada enquanto tal. Desse modo, mesmo que em geral o pequeno produtor familiar apodere-se de pequenas áreas de terra que não superam 4 módulos fiscais, o critério da dimensão da área em limites 
exatos não contribui para a caracterização desse produtor agropecuário e dessa forma de apropriação da terra.

b) $\mathrm{O}$ inciso III do Art. $3^{\circ}$ tem como determinação que o agricultor familiar tenha renda familiar predominantemente da atividade econômica ligada ao próprio estabelecimento. Essa determinação pode incorrer em distorções na coleta de dados. Por exemplo, filhos de agricultores paraibanos, que trabalham na construção civil das cidades de Campina Grande e João Pessoa, geralmente recebem salários superiores ao rendimento da atividade agrícola da sua família. Caso isso tenha sido computado no formulário do recenseador, o fato de um dos membros da família estar empregado na construção civil e contribua com a renda da família, pode descaracterizar o estabelecimento familiar, mesmo que ele continue inteiramente um estabelecimento de produção agropecuária à base do trabalho da família. Com isso, pensamos que o montante da renda, não importa de onde ela venha, não pode ser um dado que desqualifique o pequeno agricultor. O pequeno agricultor camponês é o que ele é independente de onde venha a maior parte da renda.

c) Um terceiro problema é a exigência de simultaneidade nas diretrizes. Como nos exemplos expostos acima, se o pequeno produtor possui fração de terra superior aos 4 módulos fiscais, mesmo realizando as outras diretrizes, ele é caracterizado como "não- familiar".

Hoje, o papel da agricultura familiar na segurança alimentar foi fortalecido por meio das políticas e dos instrumentos normativos que, entre outros dispositivos, contemplam propostas eficazes das políticas da agricultura familiar para a operacionalização da SAN nos Estados e nos municípios brasileiros. Um exemplo disto é o Programa de Aquisição de Alimentos (PAA). Nos últimos anos, o Brasil obteve atenção mundial com o PAA da agricultura familiar (SILVA, 2019). Um dos pilares do programa foi justamente um marco legal5: uma lei nacional exigindo que pelo menos $30 \%$ do orçamento para a alimentação escolar fosse utilizado para comprar produtos da agricultura familiar, afirma o autor.

Tal medida, ainda segundo (SILVA, 2009), oferece um ganho triplo. Em primeiro lugar, garante a boa qualidade dos alimentos oferecidos aos alunos em instituiçóes públicas, além de incentivar o consumo de alimentos frescos e saudáveis. Em segundo lugar, abre mercado e proporciona de aumento de renda para os agricultores familiares. Por fim, promove o desenvolvimento da economia local. O sucesso do PAA no Brasil despertou interesse em outros países. Abordagem muito semelhante foi implementada em pelo menos cinco países africanos (Etiópia, Malawi, Moçambique, Níger e Senegal).

5 O PAA foi instituído pelo art. 19 da Lei no 10.696, de 02 de julho de 2003, no âmbito do Programa Fome Zero. Esta Lei foi alterada pela Lei no 12.512, de 14 de outubro de 2011 e regulamentada por diversos decretos, o que está em vigência é o Decreto no 7.775, de 4 de julho de 2012. 


\section{Agricultura familiar amazonense como segurança alimentar e nutricional e abastecimento de alimentos na regiáo}

O setor agropecuário, em geral, foi o menos afetado pela pandemia e as projeções de crescimento para 2020 chegam a 2,5\%, enquanto os demais setores da economia brasileira deverão amargar forte retração de atividade (BRASIL, 2020; IPEA, 2020). Além do mais, enquanto existe preocupação intensa quanto à segurança alimentar da populaçáo mundial, no Brasil o abastecimento de alimentos ocorre de forma regular.

No AM, de acordo com SEDECTI (2020), o PIB cresceu 4,5\%, sendo o crescimento da indústria 3,91\%, os serviços 5,66\% e a agropecuária 2,13\% (puxado pela cana-de-açúcar e o milho), no primeiro trimestre deste ano, em relação ao mesmo período de 2019.

Muito embora o desempenho do setor agropecuário, em termos de valor adicionado bruto (VAB), o setor participa com apenas $7,1 \%$ da economia estadual com forte concentração para o interior $(96,1 \%)$, enquanto a indústria com $33,2 \%$ de participaçáo na economia, concentra $94,5 \%$ dela na capital Manaus por causa da indústria de transformaçáo do Polo Industrial de Manaus (PIM), em 2017(Quadro 1).

Quadro 1- VAB por atividade econômica, ano 2017

\begin{tabular}{|c|c|c|c|c|c|}
\hline \multirow{2}{*}{ UF } & \multicolumn{5}{|c|}{ Valor adicionado bruto (VAB) (RS mil) } \\
\cline { 2 - 6 } & Agropecuíria & Inđústria & Serviços & $\begin{array}{c}\text { Administraçăo } \\
\text { pública }\end{array}$ & $\begin{array}{c}\text { Total da } \\
\text { economaa }\end{array}$ \\
\hline Amazonas & $7,1 \%$ & $33,2 \%$ & $38,9 \%$ & $20,5 \%$ & $100,0 \%$ \\
\hline $\begin{array}{l}\text { Interior } \\
\text { Manaus }\end{array}$ & 96,196 & $5,5 \%$ & $14,4 \%$ & $48,9 \%$ & $24,5 \%$ \\
$3,9 \%$ & $94,5 \%$ & $85,6 \%$ & $51,1 \%$ & $75,5 \%$ \\
\hline
\end{tabular}

Fonte: Elaboração própria a partir das Contas Regionais do AM - IBGE.

Aproximadamente, $90 \%$ da agricultura amazonense é familiar, com exceção da piscicultura, onde $83 \%$ da atividade é desenvolvida por agricultores não familiares (Gráfico $1)$. 
Gráfico 1 - Número dos estabelecimentos agropecuários do AM, ano 2017.

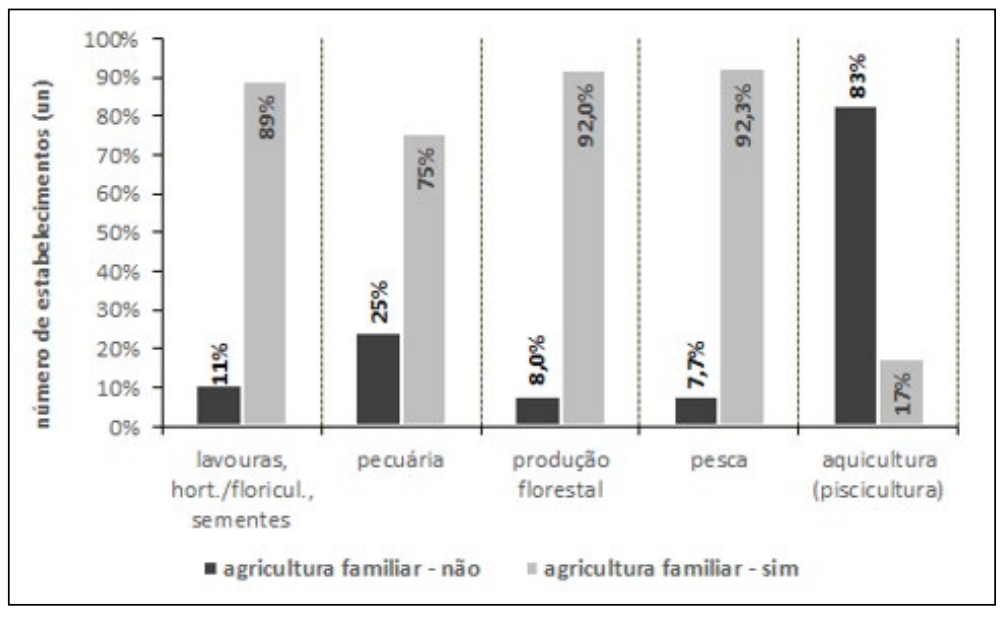

Fonte: Elaboração própria a partir do Censo Agropecuário 2017 - IBGE

Em todas as atividades, há forte concentração dos estabelecimentos rurais em áreas inferiores a 10 hectares (ha), com exceção da pecuária e piscicultura; além disso, é importante a participação de produtores sem terra nas atividades extrativas de pesca $(8,4 \%)$ e de florestas nativas $(13,4 \%)$ (Tabela 1$)$.

Tabela 1- Número e área dos estabelecimentos agropecuário do AM

\begin{tabular}{lcccc}
\hline & \multicolumn{4}{c}{ Número de estabelecimentos (\%) } \\
\cline { 2 - 5 } Atividade econômica & $\begin{array}{r}\text { inferior } \\
\text { a } 10 \text { ha }\end{array}$ & $\begin{array}{c}10 \text { a menos } \\
\text { de } 100 \text { ha }\end{array}$ & $\begin{array}{c}\text { a partir de } \\
100 \text { ha }\end{array}$ & $\begin{array}{c}\text { produtor } \\
\text { sem terra }\end{array}$ \\
\hline \hline lavoura temporária & 60,3 & 30,9 & 4,4 & 4,4 \\
horticultura e floricultura & 62,9 & 32,7 & 2,9 & 1,5 \\
lavoura permanente & 47,7 & 45,5 & 6,6 & 0,2 \\
pecuária & 19,5 & 50,6 & 29,5 & 0,4 \\
produção florestal (florestas plantadas & 50,0 & 37,8 & 12,2 & 0,0 \\
produção florestal (florestas nativas) & 58,9 & 21,4 & 6,3 & 13,4 \\
pesca & 71,5 & 17,4 & 2,6 & 8,4 \\
aquicultura & 24,3 & 57,5 & 18,2 & 0,0 \\
\hline
\end{tabular}

Fonte: Elaboração própria a partir do Censo Agropecuário 2017 - IBGE

Esses pequenos produtores rurais familiares são os “responsáveis em parte" pelo abastecimento de alimentos distribuídos e consumidos nas feiras (como a Feira da Manaus Moderna), nos supermercados, nos mercadinhos e nas redes de atacado de Manaus. "Responsáveis em parte" porque o AM não é autossustentável na produção de alimentos, sendo dependente de produtos alimentícios importados de outras Unidades da Federação (UF's) e de outros países. Segundo Oliveira e Pereira (2017), os processos produtivos de 
cultivo de feijáo-caupi e milho não atendem à crescente demanda de grãos secos no $\mathrm{AM}^{6}$. A mandioca, por sua vez, mesmo com cultivo expressivo e ocupando o segundo lugar em temos de áreas plantada na região Norte, não atende ao mercado interno, sendo necessário importar de outros estados os principais derivados da raiz: farinha e fécula. As consequências negativas disso são: evasão de divisas na economia e não geração de emprego em âmbito estadual, acrescentam os autores.

Oliveira e Pereira (2017) revelam, ainda, que o Estado se caracteriza como grande importador desses produtos alimentares (mandioca, milho e feijão), o que dificulta a soberania e a segurança alimentar da população amazonense. Além disso, nas últimas décadas, a população vem apresentando considerável expansão demográfica, o que ocasiona aumento no consumo e, consequentemente, na importação de alimentos, afirma os autores.

Por exemplo, a mandioca é uma das culturas mais exploradas no AM, mas os amazonenses ainda dependem da mandioca do Sudeste e do Sul. A produção amazonense de mandioca representou 8,4\% da produção nacional, em 2017 e, mesmo assim, o Estado ainda importou, respectivamente, $53,2 \%$ e $40,8 \%$ de mandioca do RS e de SP para suprir a demanda interna (Gráfico 2). A busca por uma maior produtividade da mandioca possivelmente levaria ao desenvolvimento sustentado do setor, a autossuficiência e reduziria a dependência externa desse produto.

Gráfico 2- Produção e importação de mandioca, ano 2017

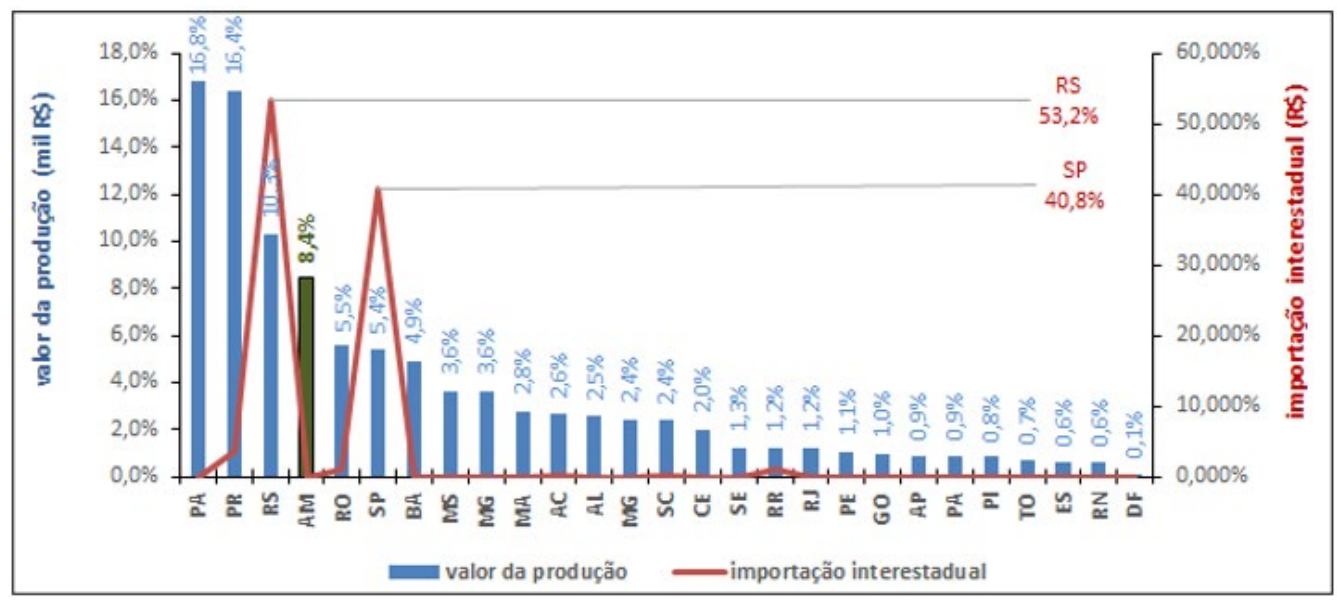

Fonte: Elaboração própria a partir dos dados da PAM/IBGE e das NFe's/SEFAZ/AM.

Aproximadamente, $40 \%$ da farinha de mandioca importada pelo AM, em 2017, veio do Paraná (PR), assim como 76,5\% da banana importada pelo Estado veio do Maranhăo (MA) (Gráfico 3).

6 Entre as causas consideradas determinantes para a não adoção de tecnologias adequadas à realidade socioambiental do AM e para o avanço do processo produtivo dessas culturas, destacam-se: solos de baixa fertilidade natural, insmos com preços elevados, baixo nível tecnológico do agricultor, incipinte serviço de assintência técnica e desconhecimento das tecnologias disponibilizadas pela pesquisa acerca desses cultivos. 
Gráfico 3- Importaçóes interestaduais de banana e de farinha de mandioca do AM, ano 2017

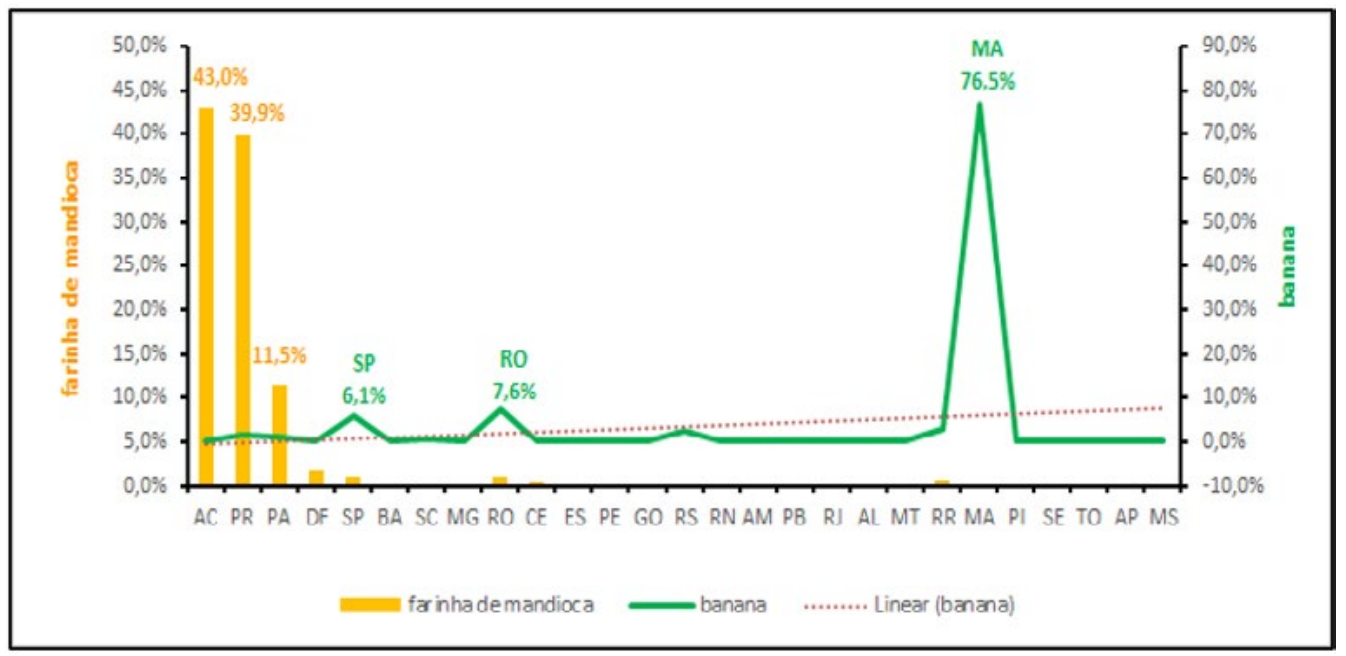

Fonte: Elaboração própria a partir dos dados da SEFAZ/AM.

A importação de alimentos pode ser considerada benéfica no que tange a preservação da floresta, todavia pode ser comprometida em caso de catástrofes, baixa produtividade dos estados exportadores, dentre outros fenômenos que possam afetar os principais produtos demandados. É importante analisar que essa lacuna no Estado pode ser vista não como uma desvantagem, mas como uma oportunidade para a agricultura familiar, além do fortalecimento da segurança alimentar, que já não é propriamente um problema no quesito regularidade do acesso, principalmente no meio rural (HOMMA et. al, p. 80, 2008).

Há a possibilidade de aumentar a produção principalmente utilizando os recursos pré-existentes, de modo a ser feito o melhor aproveitamento principalmente dos solos já utilizados, evitando assim abertura de novas áreas antes nunca utilizadas (HOMMA et. al, p. 78, 2008).

Fazendo opção por culturas perenes, levando novas tecnologias necessárias para o campo, enfatizando o uso de áreas parcialmente desmatadas e recuperando outras, é possível aumentar a participação do estado do Amazonas no setor primário, preservando saberes tradicionais nas técnicas produtivas, valorizando o agricultor familiar que já é responsável pelo abastecimento do mercado interno principalmente de verduras e hortaliças (grifo das autoras), além de garantir uma estabilidade na questão da segurança alimentar e nutricional (HOMMA et. al, 2008).

Oliveira e Pereira (2017) defendem práticas agrícolas e inovações sustentáveis que associem boas produtividades e não degradem o ambiente, vislumbrando que o uso de tecnologias adequadas à realidade das condiçóes socioambientais do AM promova uma redução da prática do sistema de cultivo tradicional com derruba e queima, uma vez que o uso de técnicas de manejo e conservação de solos possibilita o cultivo contínuo nessas áreas. 
É por isso que, segundo Gama et al (2008), a agricultura familiar amazonense possui papel fundamental para o desenvolvimento da região, evidenciando a necessidade da implementaçáo de açóes que visem ao fortalecimento dessa atividade, tais como a incorporação de novas tecnologias agropecuárias que proporcionem alto retorno econômico, que minimizem os riscos e assegurem a sustentabilidade do agronegócio familiar. Da mesma feita, Meneghetti e Souza (2015) afirmam que o espaço da agricultura familiar no Estado só pode ser entendido considerando a estrutura agrária, o ambiente físico e institucional em que ela está envolvida, o limite de uso da terra para o desenvolvimento de agrícolas, a tecnologia que usa e a que poderia ser utilizada, o processo de inovação possível, o papel institucional da categoria enquanto produtora de alimentos para o Estado.

Nessa esteira, segundo Oliveira e Pereira (2017), a Embrapa Amazônia Ocidental vem gerando tecnologias para os agricultores amazonenses, dispondo tecnologias simples e de fácil acesso, como: manejo da fertilidade do solo, arranjo espacial de plantas, cultivares mais produtivas, controle integrado de plantas daninhas, pragas e doenças que possibilitam recomendaçóes de cultivares e inovaçóes tecnológicas para o cultivo de mandioca, milho e feijão-caupi, no Estado, visando à produção de alimentos com qualidade, além de contribuir para a segurança alimentar dos produtores rurais.

Para tanto, como a agricultura familiar amazonense está concentrada $(96,1 \%)$ no interior, ela deve ser olhada como um setor altamente estratégico para a interiorização do desenvolvimento em bases sustentáveis e para a segurança alimentar regional, em face de alguns fatores:

(a) Em primeiro lugar porque a agricultura de base familiar é um canal para reduzir o nível de pobreza dos povos ribeirinhos e para promover o desenvolvimento local sustentável.

De acordo com IBGE (2018), aproximadamente, 50\% (48,1\%) da população da Regiáo Norte apresentava, em 2017, rendimento mensal domiciliar per capita de até $1 / 2$ salário mínimo e $43,1 \%$ da populaçáo viviam com rendimento inferior a US\$ 5,50 PPC (cerca de $\mathrm{R} \$ 406,00$ mensais), caracterizando situação de pobreza. Positivamente a isto, foi elevada a participaçáo de alimentos in natura ou minimamente processados no meio rural e entre famílias com menor renda na Região Norte $(58,2 \%)$, que as outras regióes brasileiras (Nordeste, 54,5\%; Sudeste, 44,9\%; Sul, 47,3\% e Centro-Oeste, 50,7\%).

Em relação ao AM, ele era o terceiro no país e o primeiro da região Norte com maior percentual de pessoas $(47,9 \%)$ vivendo a margem da pobreza com renda inferior a $\mathrm{R} \$ 406$ mensais, além do que $14,4 \%$ dos amazonenses viviam na extrema pobreza ou na miséria com cerca de $\mathrm{R} \$ 140,00$ por mês ( $1 / 4$ do salário mínimo), no mesmo período, afirma o IBGE. Estudo realizado por Yuyama et al (2007), ao analisar a segurança/insegurança alimentar em famílias urbanas e rurais no AM, mostrou que havia uma relação inversa entre insegurança alimentar e renda. Esta relação, segundo os autores, é expressiva nas áreas urbana e rural, particularmente na área urbana. Ao menor nível de renda corresponde o maior nível de insegurança alimentar, constatando-se prevalência de insegurança alimentar grave no estrato inferior de rendimento familiar (menos de 1 salário mínimo), variando entre $85,4 \%$ e $48,6 \%$ na área urbana e rural, respectivamente, afirma os autores. 
Para tanto, reduzir a fome e a subnutrição dos povos da floresta e garantir a segurança alimentar e nutricional por meio da agricultura familiar constitui uma solução não só para acabar com a fome, mas, principalmente, para promover desenvolvimento local sustentável. Para Companhola e Silva (2000), o desenvolvimento local é um processo de construção coletiva, prevalecendo as necessidades sociais e culturais, devendo estar sincronizadas com as oportunidades locais de desenvolvimento, seja nos aspectos econômicos da inserção no mercado, seja em aspectos dos recursos naturais disponíveis e de sua conservação. O desenvolvimento local deve, segundo os autores, ser acima de tudo um processo de reconstrução social, que deve se dar "de baixo para cima" e contar com a participação efetiva dos atores sociais. Corroborando com esse entendimento, Santos e Mitja (2012 apud Cruz e Valente, 2004) afirmam que uma abordagem do desenvolvimento local sustentável considera que as comunidades devem explorar características e potencialidades próprias, na busca de especialização de atividades que lhes tragam vantagens comparativas de natureza econômica, social, política e tecnológica, aumentando a renda e as formas de riqueza, respeitando a preservação dos recursos naturais renováveis.

Algumas sub-regióes amazonenses são potencialmente produtores de determinados produtos agrícolas/extrativos, os quais podem servir como matriz de desenvolvimento local. A sub-regiáo Rio Negro/Solimóes concentrava, aproximadamente, $30 \%$ da produção estadual de mandioca, em 2017, compreendendo $28,4 \%$ dos produtores beneficiados do Estado e tendo no município de Manacapuru 52,6\% da produção dessa sub-regiāo (Tabela 2 e Mapa 1).

Tabela 2- Sub-regióes do AM produtoras de mandioca, ano 2017

\begin{tabular}{|c|c|c|c|c|}
\hline \multirow[b]{2}{*}{ Ordem } & \multirow[b]{2}{*}{ Sub-regiões } & \multicolumn{3}{|c|}{ Mandioca (estimativa do município) } \\
\hline & & produção $(t)(\%)$ & $\begin{array}{l}\text { produtores } \\
\text { rurais (un) (\%) }\end{array}$ & $\begin{array}{c}\text { principal produtor em relação } \\
\text { à sub-região }(\%)\end{array}$ \\
\hline 1 & rio negro/solimões & 27,6 & 28,4 & $\begin{array}{c}\text { Manacapuru } \\
52,64\end{array}$ \\
\hline 2 & jutaí/solimões/juruá & 15,7 & 14,1 & $\begin{array}{l}\text { Tefé } \\
61,18\end{array}$ \\
\hline 3 & médio amazonas & 15,1 & 12,6 & $\begin{array}{c}\text { Itacoatiara } \\
30,79\end{array}$ \\
\hline 4 & madeira & 12,1 & 13,2 & $\begin{array}{l}\text { Manicoré } \\
47,73\end{array}$ \\
\hline 5 & purus & 8,9 & 8,8 & $\begin{array}{c}\text { Tapauá } \\
41,05\end{array}$ \\
\hline 6 & baixo amazonas & 7,7 & 6,4 & Nhamundá \\
\hline 7 & juruá & 7,3 & 6,9 & Eurunepé \\
\hline 8 & alto solimões & 3,6 & 6,4 & $\begin{array}{c}\text { Atalaia do Norte } \\
26,71\end{array}$ \\
\hline 9 & alto rio negro & 2,0 & 3,2 & $\begin{array}{l}\text { Säo Gabriel da Cachoeira } \\
44,84\end{array}$ \\
\hline & TOTAL & 100,0 & 100,0 & - \\
\hline
\end{tabular}

Fonte: Elaboração própria a partir dos dados do IDAM/SEPROR/AM 
Figura 1- Mapa dos maiores produtores de mandioca do AM, ano 2017

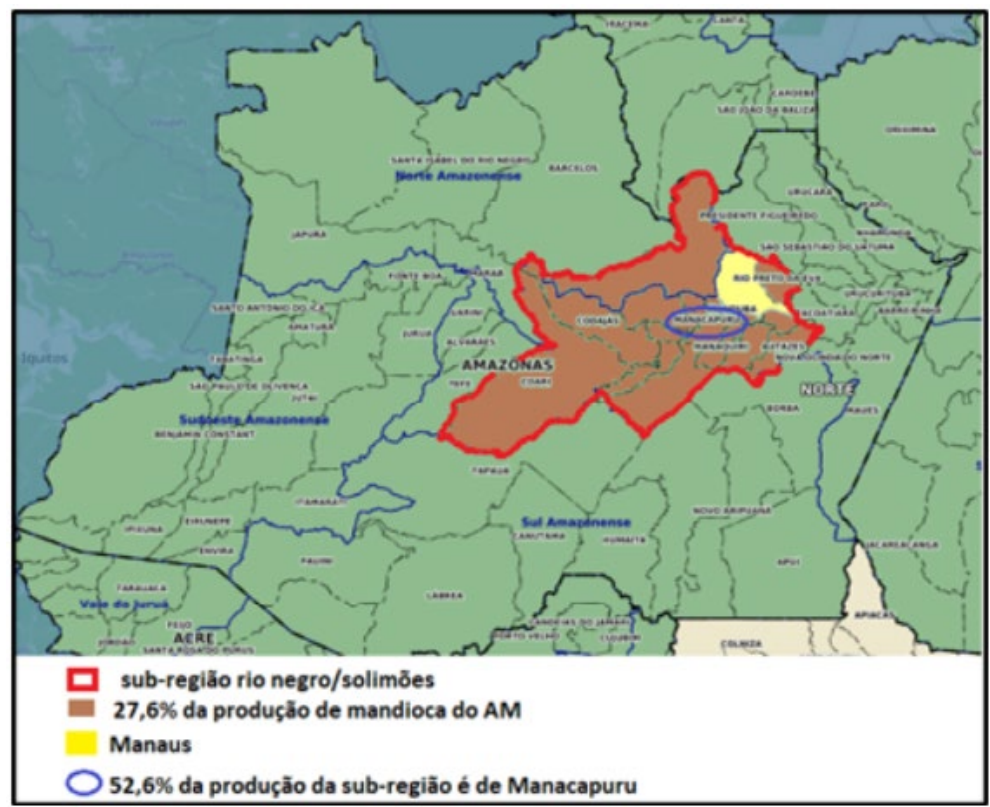

Fonte: Elaboração própria a partir dos dados do IDAM/SEPROR/AM e EstatGeo/IBGE.

(b) Em segundo lugar porque alguns produtos agrícolas e extrativos peculiares da Regiáo Norte são altamente reconhecidos no Brasil e no resto do mundo, o que pode leva-los a serem protegidos por lei e/ou favorecer ao desenvolvimento local sustentável.

As qualidades nutritivas, os saberes tradicionais e a procedência desses produtos são fatores essenciais para sua valorização, o desenvolvimento da cadeia produtiva local e a diversidade produtiva na propriedade rural familiar. Alguns "cases" podem elucidar este segundo ponto no que se refere à valorização e ao reconhecimento dos nossos produtos:

O case do abacaxi se refere a considerar o produto como Patrimônio Cultural de Natureza Imaterial do Amazonas:

Recentemente, o abacaxi de Novo Remanso recebeu o selo de Indicação Geográfica (IG), na categoria Indicação de Procedência (IP) ${ }^{7}$, pelo Instituto Nacional de Propriedade Industrial (INPI), com publicação na Revista da Propriedade Industrial (GLAY, 2020). Em virtude disto, o abacaxi está a um passo de se tornar Patrimônio Cultural de Natureza Imaterial do Amazonas, que é uma proposta de Projeto de Lei do Deputado Estadual João Luiz, cujo objetivo é valorizar e fortalecer, cada vez mais, o aprimoramento das técnicas de cultivo e manejo do abacaxi utilizadas na região, afirma a autora.

A sub-região do médio amazonas, ao longo dos anos, tem-se mantido no ranking da produção de abacaxi no AM, alcançando uma participação média de 75,2\% em

7 O guaraná de Maués, o peixe ornamental de Barcelos e a farinha do Uarini são produtos também com selo de qualidade e localidade do Amazonas. 
relação à produção estadual, sendo que o Novo Remanso (distrito de Itacoatiara) tem uma participação média de $72,5 \%$ e $96,5 \%$ em relação à produção estadual e à produção da subregiáo, respectivamente (Tabela 3 ).

Tabela 3- Participação da produção de abacaxi do AM na sub-região médio amazonas, ano 2014-2019

\begin{tabular}{|c|c|c|c|c|c|c|c|}
\hline \multirow{2}{*}{ Região } & \multicolumn{6}{|c|}{ Produção de Abacaxi (mil frutos) ( $\%$ ) } & \multirow{3}{*}{$\begin{array}{c}\text { Participação } \\
\text { média }(\%)\end{array}$} \\
\hline & 2014 & 2015 & 2016 & 2017 & 2018 & 2019 & \\
\hline AM & 100,0 & 100,0 & 100,0 & 100,0 & 100,0 & 100,0 & \\
\hline Sub-região médio amazonas / AM & 74,1 & 72,9 & 76,0 & 76,4 & 77,1 & 74,6 & 75,2 \\
\hline Novo Remanso / AM & 69,0 & 69,8 & 73,9 & 74,3 & 75,3 & 73,1 & 72,5 \\
\hline Novo Remanso / Sub-região médio amazonas & 93,2 & 95,7 & 97,3 & 97,2 & 97,7 & 98,0 & 96,5 \\
\hline
\end{tabular}

Fonte: Elaboração própria a partir dos dados do IDAM/SEPROR/AM

O abacaxi tem contribuído, ao longo do tempo, para geração de renda e emprego aos agricultores familiares de abacaxi no AM. A participação média do número de beneficiários da sub-região do médio amazonas em relação ao AM corresponde a 39,4\%, a do Distrito de Novo Remando em relação ao AM corresponde a 33,8\% e do Novo Remanso em relação à sub-regiáo do médio amazonas corresponde a 85,9\% (Tabela 4).

Tabela 4- Participação dos produtores rurais do AM na sub-região médio amazonas, ano 2014-2019

\begin{tabular}{|c|c|c|c|c|c|c|c|}
\hline \multirow{2}{*}{ Região } & \multicolumn{6}{|c|}{ Produtores familiares ( $n^{\circ}$ de beneficiários) $(\%)$} & \multirow{3}{*}{$\begin{array}{c}\text { Participação } \\
\text { média }(\%)\end{array}$} \\
\hline & 2014 & 2015 & 2016 & 2017 & 2018 & 2019 & \\
\hline AM & 100,0 & 100,0 & 100,0 & 100,0 & 100,0 & 100,0 & \\
\hline Sub-região médio amazonas / AM & 41,9 & 38,9 & 40,0 & 41,4 & 37,6 & 36,4 & 39,4 \\
\hline Novo Remanso / AM & 33,2 & 33,0 & 35,2 & 36,7 & 32,5 & 32,1 & 33,8 \\
\hline Novo Remanso / Sub-região médio amazonas & 79,4 & 85,0 & 87,9 & 88,5 & 86,3 & $\$ 8,2$ & 85,9 \\
\hline
\end{tabular}

Fonte: Elaboração própria a partir dos dados do IDAM/SEPROR/AM

O case do açaí refere-se ao seu manejo sustentável. Para Sacramento et al (2015) e Fraxe et al (2007) o açaí é fonte de renda e segurança alimentar para milhares de pequenos agricultores familiares ribeirinhos amazônicos, muito embora o caráter multifuncional do meio rural na região. 
Segundo Martinot et al (2017), no AM, até recentemente, a coleta do açaí era feita exclusivamente em áreas de ocorrência natural da espécie e o processamento dos frutos era realizado de modo artesanal em pequenos estabelecimentos familiares, para o consumo local; mas, com o crescente consumo em outras regiōes não produtoras e das exportaçóes para outros países, o açaí vem se tornando um cultivo agroindustrial. Os autores acreditam que a crescente demanda de mercado pelo produto não venha a ser atendida em razão da oferta limitada do sistema extrativo, imposta por fatores naturais e socioeconômicos internos às unidades familiares de produção. Agricultores podem optar por não coletar comercialmente o açaí, mesmo vivendo em áreas com relevante potencial produtivo, por razōes de ordem logística, comercial, fundiária e política. Por outro lado, em resposta ao aumento da demanda de mercado, as famílias podem estar optando pela intensificaçáo da produção mediante a domesticação do açaí em sistemas de cultivo agrícola, complementam os autores.

O Gráfico 3 mostra essa realidade apontada por Martinot et al (2017). Muito embora a atividade extrativa ainda seja predominante, há um declíneo da produçáo do açaí nativo em detrimento do cultivado, ao longo do tempo, $-8,7 \%$, abrindo espaço cada vez mais para a produçáo manejada. Da mesma forma acontece com os agricultores familiares, é predominante a quantidade de produtores familiares na coleta do fruto extrativo, muito embora estável, ao longo do período.

Gráfico 3- Produção e número de produtores familiares de açaí no AM, ano 2014-2019.

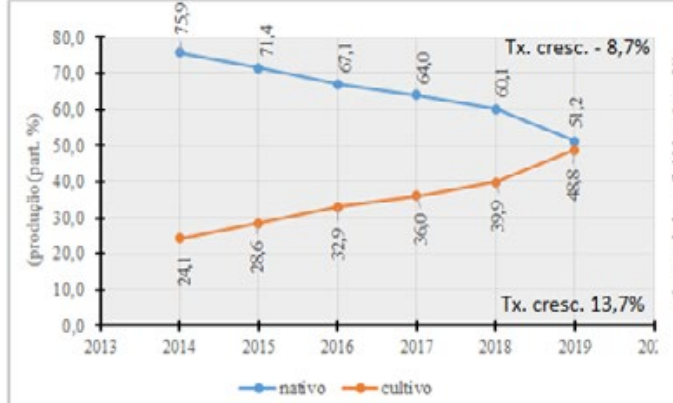

(a)

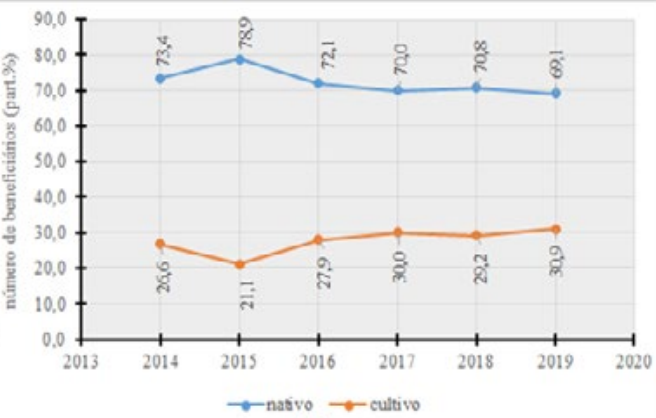

(b)

Fonte: Elaboração própria a partir dos dados do IDAM/SEPROR/AM.

Segundo Fraxe et al (2007), a agricultura familiar do AM está baseada em Sistemas Agroflorestais (SAF's) diversificados, os quais apresentam grande potencial como componente de estratégias de desenvolvimento local, pois diversifica a produção nas unidades produtivas, propiciando maior proteçáo contra as variaçóes dos preços e menor pressão sobre a capacidade dos mercados de absorver um determinado produto. Além de contribuírem para a manutençấo da biodiversidade da comunidade edáfica do solo na regularização de ciclagem de nutrientes e a recuperação de fragmentos florestais, matas ciliares, áreas degradadas e paisagens (FRAXE et al, 2007 apud NAIR, 1991; BAGGIO, 1992; AMADOR; VIANA, 1998; WANDELLI et al, 2000). Os SAF's se alinham à proposta de Rocha e Brandenburg (2003) sobre a busca por uma agricultura familiar sustentável baseada na agroecologia. 
Segundo os autores, considerando que a sustentabilidade agrícola pode ser definida, de modo geral, como a atividade econômica capaz de suprir as necessidades presentes, sem restringir as opçóes para o futuro. Ou dito de outra forma, os recursos naturais que seráo necessários para o futuro, não podem ser esgotados na satisfaçáo de consumo do presente. Será só através da compreensão profunda dos ecossistemas rurais, que envolvem os sistema agrícolas de cada regiāo, que se chegaria a medidas coerentes com uma agricultura realmente sustentável.

O estudo de Martinot et al (2017), sobre a produção familiar e o manejo agroextrativista da espécie nativa no AM, o açaí-da-mata (E. precatória), revelou que nos sistemas cultivados (a) a menor altura das árvores facilita o trabalho da coleta; (b) apresentam densidade populacional muito superiores do que nos povoamentos florestais nativos, particularmente no monocultivo; (c) a produção e o trabalho de coleta podem ser concentrados em uma área menor, com redução do esforço e aumento significativo do rendimento do trabalho; e, (d) apresentam características favoráveis ao manejo sustentável.

Tabela 5- Estrutura populacional do açaí sob diferentes condições de manejo em áreas de agricultura familiar no baixo rio Manacapuru, Manacapuru (AM)

\begin{tabular}{cccc}
\hline Sistema de manejo & $\begin{array}{c}\text { altura média } \\
(\mathbf{m})\end{array}$ & $\begin{array}{c}\text { diâmetro médio } \\
\text { (DAP em cm) }\end{array}$ & $\begin{array}{c}\text { densidade média } \\
\text { (plantas/ha) }\end{array}$ \\
\hline Mata extrativa & 14,7 & 12,4 & 517 \\
Sistema agroflorestal & 10,7 & 10,2 & 910 \\
Monocultivo & 4,5 & 3,5 & 3460 \\
\hline
\end{tabular}

Fonte: Martinot el al (2017).

Estudo realizado por Pepper e Alves (2015) revela que agricultores familiares que praticam manejo tradicional do açaí no Rio Canaticu, Ilha do Marajó já adotam medidas para oferecer açaí de maior qualidade por meio de práticas que requerem um mínimo de 50\% de espécies florestais nativas permaneçam dentro de áreas de produção de açaí. Desta forma, eles náo apenas moderam o incentivo para intensificar a concentraçáo da palmeira do açaí, mas também mantêm a integridade das áreas florestais sob manejo. Os autores também revelam que uma forma para os produtores familiares em áreas de várzea continuarem a beneficiar da demanda global de açaí é se conectar a mercados que valorizem o manejo tradicional e agroecológico. A certificação de manejo sustentável aplicada à área sob manejo, em vez de a um produto específico, poderia apoiar a meta dos agricultores de diversificar as fontes de renda.

\section{(c) agricultura familiar amazonense como abastecimento de alimentos na regiáo}

No caso da regiáo amazônica, o abastecimento possui características distintas de outras regióes como a sazonalidade peculiar de seus rios (PINTO e MORAES, 2010).

De acordo com Moraes e Schor (2010), as cidades do AM possuem grande dependência em relação à Manaus, que as abastece com bens e serviços, inclusive gêneros 
alimentícios, caracterizando uma forte articulaçấo entre as cidades do interior e a capital. Em todos os municípios do AM, o abastecimento com gêneros alimentícios depende primordialmente do transporte fluvial, afirmam os autores. Além do que, a sazonalidade dos rios, com os regimes de enchente e vazante, caracteriza o principal elemento que influencia nos fluxos entre as cidades em vários aspectos, complementam os autores.

Ainda segundo Moraes e Schor (2010), a questão alimentar é um assunto transversal no âmbito do interesse social e das ciências, por tratar um tema cuja negligência resulta em consequências muito evidentes. O pioneiro na discussão do tema no Brasil, sem dúvidas, foi Josué de Castro com sua obra Geografia da Fome, lançado em 1946, na qual o autor utiliza um tom de denúncia ao abordar a questão da fome no Brasil, afirma os autores.

Ainda segundo os autores, essa "geografia da fome" no AM possui limitaçóes geográficas, que devem ser consideradas nos estudos sobre o abastecimento alimentar. Para tanto, eles substituem o nome "geografia da fome" adotado por Josué de Castro por "geografia do abastecimento" em virtude de uma maior interação entre Manaus e as cidades localizadas ao longo das calhas dos rios Solimóes e Negro, que em seus estudos deu-se por causa da análise do custo de vida nas cidades de Manacapuru e Coari, localizadas na calha do rio Solimóes.

Hanada (2014) expõe que os agricultores familiares tradicionais exercem um papel fundamental na manutenção da vegetação natural da Amazônia Central; e, os sistemas de produção adotados por esses agricultores têm apresentado elevados patamares de autossuficiência e estabilidade, conservando a sócio biodiversidade, segurança alimentar das comunidades rurais, dispersão e resgate de espécies vegetais. Portanto, os desafios na agricultura são inúmeros e há necessidade que as açóes de pesquisas e extensão estejam estruturadas e integradas, afirma o autor.

Para ele, ainda, característica do cultivo do solo na várzea e a terra firme aliado a um sistema de transporte fluvial precário, em uma região onde os rios são as estradas, torna distinta a análise do sistema de abastecimento das cidades do Amazonas. É por isso que Maluf (2020) explica, entấo, que o abastecimento engloba um conjunto diverso e complexo de atividades mediando o acesso aos alimentos e sua produção, atividades nas quais estão envolvidos atores sociais com perspectivas muitas vezes conflitantes, entre agentes econômicos privados, organismos de Estado, organizaçóes de consumidores e de produtores familiares.

$\mathrm{Na}$ tentativa de ampliar a ideia de Moraes e Schor (2010) de "geografia do abastecimento" para "sub-regióes do abastecimento", é notável o desempenho da atividade pesqueira artesanal em sub-regióes do AM e sua importâcia para a segurança alimentar regional.

As sub-regióes jutaí/solimóes/juruá detinha, em 2017, 34,1\% de toda a produção artesanal do Estado, mas, em contrapartida, o número de pescadores eram maiores na sub-regiáo rio negro/solimóes, com $26,9 \%$ dos pescadores familiares, no mesmo período avaliado (Quadro 1). 
Quadro 1- Pesca artesanal nas sub-regióes do AM, ano 2017

\begin{tabular}{|c|c|c|}
\hline \multirow{2}{*}{ sub-regiões } & \multicolumn{2}{|c|}{ Pesca artesanal } \\
\cline { 2 - 3 } & $\begin{array}{c}\text { pescadores } \\
\text { embarcações até } \\
19,9 \text { (un) }\end{array}$ & produção (t) \\
\hline alto solimões & $17,9 \%$ & $8,8 \%$ \\
\hline jutaí/solimỗes/juruá & $20,6 \%$ & $34,1 \%$ \\
\hline purus & $14,4 \%$ & $16,7 \%$ \\
\hline juruá & $4,3 \%$ & $2,2 \%$ \\
\hline madeira & $5,0 \%$ & $1,4 \%$ \\
\hline alto rio negro & $1,9 \%$ & $1,0 \%$ \\
\hline rio negro/solimões & $26,9 \%$ & $28,3 \%$ \\
\hline médio amazonas & $4,7 \%$ & $3,7 \%$ \\
\hline baixo amazonas & $4,3 \%$ & $3,8 \%$ \\
\hline TOTAL & $100,0 \%$ & $100,0 \%$ \\
\hline
\end{tabular}

Fonte: Elaboração própria a partir dos dados do IDAM/SEPROR/AM.

A pesca artesanal na Amazônia brasileira é de vital importância para o fornecimento de alimento à populaçáo local e como fonte de renda, obtida através da comercialização do pescado nos mercados dos centros urbanos regionais e da exportação para o sul do país ou mesmo para o exterior (ISAAC et al, 1996; LIMA et al 2016).

Para tanto, especificamente para a política de SAN, as açóes imediatas emergenciais devem buscar objetivos permanentes que vão além da pandemia. Deve-se chegar a formas de combater problemas como a subnutrição, a fome, o acesso a uma alimentação adequada e saudável para todos, considerando o modo de produção e distribuição dos alimentos e ainda promover uma diversidade cultural e ecológica (MALUF, 2020).

\section{Consideraçóes finais}

A segurança alimentar e a agricultura familiar, além de terem uma relação extremamente direta, são temáticas transversais, que envolvem políticas públicas direcionadas à questão da pobreza, da fome, da sustentabilidade e do desenvolvimento local.

Nessa esteira, pensar em segurança alimentar é pensar nos grandes desafios para se manter o direito ao acesso regular e permanente a alimentos de qualidade e em quantidade suficiente, especialmente, nesses tempos de pandemia. No entanto, vale destacar que a agricultura foi a única atividade que ainda não apresentou retração econômica diante da crise de saúde pública universal provocada pela doença covid-19, em particular no Brasil.

Como as políticas públicas voltadas para a segurança alimentar estendem essa dimensão para o desenvolvimento local, é mister que a agricultura de base familiar no País 
continue sendo responsável pelos processos de produção e abastecimento de alimentos, o que favorece comunidades rurais e o desenvolvimento local sustentável.

Estados como o do Amazonas, onde a atividade agropecuária participa apenas com $7 \%$ da economia estadual e onde $96 \%$ do setor está voltado para o interior, a agricultura familiar desempenha papel estratégico para o desenvolvimento da região. A agricultura de base familiar amazonense é um canal para reduzir o nível de pobreza dos povos ribeirinhos, assegurar a segurança alimentar e nutriconal local e inter-regional e manter os recursos das florestas com produção de alimentos. Mas, há necessidades da implementação de açôes que visem ao fortalecimento dessa atividade, especialmente, políticas públicas de fortalecimento de alguns setores agrícolas tradicionais na regiâo, como a pesca artesanal, a cultura da mandioca, a fruticultura do açaí e do abacaxi, entre outros.

Assegurar a sustentabilidade do agronegócio familiar na região é sinômimo de diversificar a atividade econômica estadual e de interiorizar o desenvolvimento. O processo de interiorização através da agricultura, ao considerar os atores envolvidos no processo produtivo e suas demandas, garante a perpetuação de saberes tradicionais, métodos de cultivo e manutençáo da cultura do povo amazonense.

E, muito embora ser o AM um grande importador de alimentos - o que dificulta a soberania e a segurança alimentar da população amazonense - para alguns estudiosos isto não deve ser analisado como um comportamento negativo e sim um fator positivo associado a manutenção da cobertura florestal da regiāo. Outro aspecto é que a intensificação das atividades agrícolas no interior do Estado pode vir a fazer melhor uso de áreas já degradadas.

É importante salientar que o Estado, embora concentre suas atividades econômicas nos setores terciário e secundário, possui condiçóes de incrementar sua economia, além de desenvolver localidades do interior através do fortalecimento da agricultura familiar que, por sua vez, aumentaria a segurança alimentar e nutricional tanto dos centros urbanos quanto das zonas rurais.

Existem muitas lacunas ainda a serem estudadas com respeito a segurança alimentar e o abastecimento de alimentos no AM, como: o aumento da produtividade nas atividades agrícolas, as cadeias produtivas, os processos logísticos para escoamento da produção rural, os investimentos para o setor agrícola, a dependência de alimentos, entre outros temas transversais que se expandem quando se relaciona a segurança alimentar e nutricional e a agricultura familiar.

\section{Referências}

ABRAMOVAY, R. Agricultura Familiar e Reforma Agrária. Estudo da Dimensão Territorial do PPA. Brasília: CGEE, 2006.

ABRAMOVAY, R. Agricultura familiar e desenvolvimento territorial. Reforma Agrária Revista da Associação Brasileira de Reforma Agrária - vols. 28 nºs 1,2 3 e 29, nº1 - Jan/ dez 1998 e jan/ago 1999. 
BELIK, Walter. Perspectivas para segurança alimentar e nutricional no Brasil. Saúde e Sociedade v.12, n.1, p.12-20, jan/jun 2003.

BEZERRA, G. J.; SCHLINDWEIN, M. M. Agricultura familiar como geração de renda e desenvolvimento local: uma análise para Dourados, MS, Brasil. Interaçóes, Campo Grande, MS, v. 18, n. 1, p. 3-15, jan./mar. 2017.

BRASIL. Boletim Macro Fiscal da SPE/ME. Brasília, maio de 2020. Disponível em: http:/www.fazenda.gov.br/centrais-de-conteudos/publicacoes/conjuntura-economica/ boletim-macrofiscal/boletim-macrofiscal-maio-2020-v12.pdf. Acesso em: 01 de junho 2020.

CAMPANHOLA, C.; SILVA, J. G. da. Desenvolvimento local e a democratização dos espaços rurais. Cadernos de Ciência \& Tecnologia, Brasília, v.17, n.1, p.11-40, jan./abr. 2000 .

CORONA, H. M. P.; PEREIRA, A. A. Agricultura familiar e segurança alimentar e nutricional: a comunidade da península da ilha do cavernoso no município de Candói/ PR. Cronos: R. Pós-Grad. Ci. Soc. UFRN, Natal, v. 14, n.2, p.108 - 128 jul./dez. 2013, ISSN 1518-0689.

Com pandemia, aumenta demanda por produtos orgânicos. Disponível em: https:// ciorganicos.com.br/noticia/com-pandemia-aumenta-demanda-por-produtos-organicos/. Acesso em: 04/06/2020.

COSTA, José A. F, SOLA, Fernando, SALTORATO, Patrícia. Segurança alimentar: reflexóes sobre a posiçáo brasileira e seus potenciais políticos e jurídicos. R.Vianna Sapiens. V8, n 1, p. 227-256. Juiz de Fora, jan/jun 2017.

CUSTÓDIO et al. Segurança alimentar e nutricional e a construção de sua política: uma visão histórica. Segurança Alimentar e Nutricional. Campinas. V. 18, n 1, p.1-10, 2011.

FRAXE, T. J. P., PEREIRA, H. P. e WITKOSKI, A. C. (Orgs.). Comunidades Ribeirinhas Amazônicas: modos de vida e uso dos recursos naturais. Manaus: EDUA, 2007.

GAMA, A. da S.; LIMA, H. N.; GONÇALVES, J. R. P.; TEIXEIRA, W. G.; BENTES, J. L. da. Sistema de Produçáo de Tomate em Substrato para Agricultura Familiar na Regiáo Metropolitana de Manaus. Seminário de Pós-Graduação na Embrapa Amazônia Ocidental , 2008.

GLAY, J. Cultivo do abacaxi de Novo Remanso pode se tornar Patrimônio Imaterial do Amazonas. Caboco, o paortal de notícias da Amazônia. Disponível em: < https:// portalcaboco.com.br/amazonas/cultivo-do-abacaxi-de-novo-remanso-pode-se-tornarpatrimonio-imaterial-do-amazonas/>. Acesso em: 16 de junho de 2020. 
HANAD, R. E. Os desafios para a consolidação da agricultura no estado do Amazonas. Anais da 66a REUNIÁO ANUAL DA SBPC - RIO BRANCO, AC - JULHO/2014.

HOMMA, A. K. O.; ALVES, A. R. P.; ALVES, S. de M.; FRANCO, A. A. Governança e Segurança Alimentar na Amazônia. R. Est. Pará., Belé, v.1, n. 1, jan/abr., 2008.

IBGE. Contas Nacionais Trimestrais, $1^{\circ}$ tri/2020, Coordenação de Contas Nacionais/ IBGE, 2020.

IBGE. Síntese de indicadores sociais: uma análise das condições de vida da população brasileira : 2018 / IBGE, Coordenação de População e Indicadores Sociais. - Rio de Janeiro : IBGE, 2018.

IBGE. Censo Agropecuário 2006. Agricultura Familiar. Brasil, Grandes Regióes e Unidades da Federação. Ministério do Planejamento, Orçamento e Gestão/IBGE, 2010.

IPEA. Instituto de Pesquisa Econômica Aplicada. Carta de Conjuntura Economia Agrícola, no 47, $2^{\circ}$ trimestre de 2020. Disponível em: https://www.ipea.gov.br/portal/ images/stories/PDFs/conjuntura/200526_economia_agricola.pdf. Acesso em: 01 junho de 2020.

ISAAC, V. J.; MELSTEIN, A.; RUFFINO, M. L. A pesca artesanal no Baixo Amazonas: análise multivariada da captura por espécie. Acta Amazônica 26(3): 185-208. 1996.

LIMA, M. A. L.; FREITAS, C. E. de C.; MORAES, S. M. de; DORIA, C. R. da C. Pesca artesanal no município de Humaitá, médio Rio Madeira, Amazonas, Brasil. Bol. Inst. Pesca, São Paulo, 42(4): 914-923, 2016.

MAHAR, Dennis J. Desenvolvimento econômico da Amazônia: uma análise das políticas governamentais. Rio de Janeiro: Ipea/Inpes, 1978. 259 p.

MALUF, R. S. Comer em tempos de pandemia e após. Disponível em: <https://portal. ufrrj.br/wp-content/uploads/2020/04/MalufR-Comer-em-tempos-de-pandemia-eap\%C3\%B3s.pdf>. Acesso em: abril, 2020.

MARTINOT, J. F.; PEREIRA, H. S.; SILVA, S. C. P. Coletar ou Cultivar: as escolhas dos produtores de açaí-da-mata (Euterpe precatoria) do Amazonas. Rev. Econ. Sociol. Rural., vol.55, n.4, 2017.

MATTEI, L. O papel e a importância da agricultura familiar no desenvolvimento rural brasileiro contemporâneo. Rev. Econ. NE, Fortaleza, v. 45, suplemento especial, p. 8391, out./dez., 2014.

MITIDIERO JUNIOR, M. A.; BARBOSA, H. J. N.; SÁ, T. H. de. Quem produz comida para os brasileiros? 10 anos do censo agropecuário 2006. Revista Pegada, vol. 18, n.3, Setembro-Dezembro, 2017. 
MORAES, A. de O.; SCHOR, T. MERCADOS, TABERNAS E FEIRAS: custo de vida nas cidades na calha do Rio Solimóes. Mercator, v. 9, nr. 19, 2010.

OLIVEIRA, I. J. de; PEREIRA, M. C. N. Transferência de conhecimentos para adoçáo de inovaçáo tecnológicas nas culturas alimentares pelos pequenos agricultores do estado do Amazonas. Embrapa Amazônia Ocidental. Manaus, AM, 2017.

PEPPER, L. G.; ALVES, L. de F. N. O açaí ribeirinho certificado: uma forma de garantir o reconhecimento de um produto diferenciado e de assegurar renda duradoura para ribeirinhos do Estuário Amazônico. Cadernos de Agroecologia, v. 10, no 3, 2015.

PINTO, M. A. T.; MORAES, A. de O. Espaço e economia: crise e perspectivas no abastecimento em Manaus, Amazonas, Brasil. Revista Geográfica da América Central, 2 (47E). Recuperado em https://www.revistas.una.ac.cr/index.php/geografica/article/ view/2672.

PIRES, L. N.; CARVALHO, L.; XAVIER, L. L. COVID-19 e desigualdade: a distribuiçáo dos fatores de risco no Brasil. Disponível em: https://www.researchgate. net/publication/340452851_COVID-19_e_Desigualdade_no_Brasil. Acesso em: 04/06/2020.

REZENDE, E. A.; RIBEIRO, M. T. F. O cupuaçu é nosso? aspectos atuais da biopirataria no contexto brasileiro. RGSA - Revista de Gestáo Social e Ambiental, v. 3, no 2, p. 5374, maio-ago., 2009.

ROCHA, A. J. R. da. Políticas públicas, agricultura familiar e desenvolvimento territorial: uma análise dos impactos socioeconômicos do PRONAF no território médio Jequitinhonha - MG. Texto para Discussão no 1693. Brasília, IPEA, 2012.

ROCHA, J. M. da; BRANDENBURG, Alfio. Limites e desafios da agricultura familiar: a sustentabilidade em questão. REDES, Santa Cruz do Sul, v. 8, n. 2, p. 93-104, 2003.

SACRAMENTO, J. M. C., KALSING, J. e SCHULTZ, C. Açaí no Norte e juçara no Sul: a necessidade do estudo de cadeias de produtos. Cadernos de Agroecologia, v. 10, n. 3, 2015.

SANTOS, A. M. dos; MITJA, D. Agricultura familiar e desenvolvimento local: os desafios para a sustentabilidade econômico-ecológica na comunidade de Palmares II, Parauapebas, PA. Interaçóes, Campo Grande, v. 13, n. 1, p. 39-48, jan./jun. 2012.

SCHNEIDER, S. Teoria social, agricultura familiar e pluriatividade. Revista brasileira de ciências sociais, $\boldsymbol{R B S C}$. vol. 18 no. 51, fev., 2003.

SEDECTI. Secretaria de Estado de Desenvolvimento Econômico, Ciência, Tecnologia e Inovação. PIB do Amazonas teve crescimento de 4,50\% no primeiro trimestre. 
Disponível em: < http:/www.amazonas.am.gov.br/2020/06/pib-do-amazonas-tevecrescimento-de-450-no-primeiro-trimestre/>. Acesso em: 15 de junho 2020.

SILVA, J. G, da. Agricultura familiar e sustentabilidade. ONU Brasil. Artigo publicado em 14/06/2019. Disponível em: https://nacoesunidas.org/artigo-agricultura-familiar-esustentabilidade/. Acesso em: 06/04/2020.

VASCONCELlOS, A. B. P. de A.; MOURA, L. B. A. de. Segurança alimentar e nutricional: uma análise da situação da descentralização de sua política pública nacional. Cad. Saúde Pública, 34 (2), 2018.

Vendas de alimentos saudáveis crescem na pandemia e produtores buscam novas estratégias. Disponível em :https://ciorganicos.com.br/noticia/vendas-de-alimentossaudaveis-crescem-na-pandemia-e-produtores-buscam-novas-estrategias/. Acesso em: 04/06/2020.

YUYAMA, L. K.O; AGUIAR, J. P.L; PANTOJA, L.; MAEDA, R. N.; MELO, T.; ALENCAR, F. H.; NASCIMENTO, A. M. M.; NEGREIROS, N. M. A.; CORRÊA, A. M. S.; PÉREZ-ESCAMILLA, R. Segurança/insegurança alimentar em famílias urbanas e rurais no estado do Amazonas: I. Validação de metodologia e de instrumento de coleta de informação. Act Amazonia. v. 37, n. 2, p. 247-252, 2007. 